\title{
Coronavirus Disease-2019 Pneumonia and Pulmonary Embolism: Presentation of Four Cases
}

\author{
Fariba Alikhani ${ }^{1}$, Marzieh Aalinezhad ${ }^{2}$, Mostafa Haji Rezaei ${ }^{3}$, Pouya Akbari ${ }^{4}$, Marzieh Hashemi ${ }^{5}$
}

\begin{abstract}
Since the beginning of the Coronavirus Disease-2019 (COVID-19) outbreak, elevated D-dimer levels as an acute-phase reactant have been reported in some patients. Additionally, the patients with pneumonia are at increased risk of developing thromboembolic events. Diagnosing acute pulmonary embolism and deep vein thrombosis can be challenging in SARS-CoV2-positive patients. Here, we report four patients with COVID-19 pneumonia to highlight the possibility of acute thromboembolism in these patients. The physicians should be aware of this complication and even consider prophylactic anticoagulant therapy in proper clinical settings.

Keywords: Acute pulmonary embolism, COVID-19, D-dimer levels.

Indian Journal of Critical Care Medicine (2020): 10.5005/jp-journals-10071-23587
\end{abstract}

\section{INTRODUCTION}

In December 2019, cases of pneumonia of unknown cause were reported in Wuhan city, China. Soon after, the causative agent was found to be SARS-CoV2. ${ }^{1,2}$ The outbreak of the disease, known as Coronavirus Disease-2019 (COVID-19), was declared a pandemic in March 2020.

An elevated D-dimer is generally considered to be associated with deep vein thrombosis (DVT) and acute pulmonary embolism (APE). ${ }^{3}$ However, increased D-dimer levels have been reported with other conditions, such as advanced age, pregnancy, malignancies, inflammatory processes, and peripheral arterial diseases ${ }^{4-6}$ During the COVID-19 pandemic, elevated levels of D-dimer have been reported in some patients, even without evident DVT or APE. ${ }^{7,8}$

Here, we report four different patients from Isfahan, Iran, with acute APE and reverse transcription polymerase chain reaction (RT-PCR)-confirmed COVID-19 infection.

\section{Case Descriptions}

\section{Case 1}

Figure 1 illustrates the case of an 86-year-old male admitted to our hospital with fever, cough, and dyspnea. He was hospitalized for 10 days. On admission his blood tests showed a white blood cell (WBC) count of $10.30\left(10^{3} / \mu \mathrm{L}\right)$ with $69.4 \%$ neutrophils and $20.7 \%$ lymphocytes, a platelet count of $490\left(10^{3} / \mu \mathrm{L}\right)$, an erythrocyte sedimentation rate (ESR) of $55 \mathrm{~mm} /$ hour, and a C-reactive protein (CRP) of $79 \mathrm{mg} / \mathrm{L}$. On the third day of admission, the patient underwent pulmonary computed tomography (CT) angiography and lower limb compression ultrasonography due to deterioration in his clinical condition and elevated D-dimer levels (14,496 ng/ $\mathrm{mL}$ ). The lower limb compression ultrasound was negative, but his CT angiography revealed bilateral filling defects within the lobar and segmental branches of the pulmonary artery diagnostic for APE.

\section{Case 2}

Figure 2 depicts the case of a 42-year-old female admitted to our hospital for 33 days. On admission, she had fever, dyspnea, cough, and diarrhea. Increased values of CRP (141 mg/L), ESR
1,2,4 Department of Radiology, Isfahan University of Medical Sciences, Isfahan, Iran

${ }^{3}$ Infectious Diseases Research Center, Kashan University of Medical Sciences, Kashan, Isfahan, Iran

${ }^{5}$ Department of Pulmonology, Amin Hospital, Isfahan University of Medical Sciences, Isfahan, Iran

Corresponding Author: Marzieh Aalinezhad, Department of Radiology, Isfahan University of Medical Sciences, Isfahan, Iran, Phone: +989132888457, e-mail: marzieh.aalinezhad@med.mui.ac.ir

How to cite this article: Alikhani F, Aalinezhad M, Haji Rezaei M, Akbari P, Hashemi M. Coronavirus Disease-2019 Pneumonia and Pulmonary Embolism: Presentation of Four Cases. Indian J Crit Care Med 2020;24(9):873-876.

Source of support: Nil

Conflict of interest: None

(93 mm/hour), and D-dimer ( $806 \mathrm{ng} / \mathrm{mL}$ ) were present. Her blood test also revealed a WBC count of $10.60\left(10^{3} / \mu \mathrm{L}\right)$ with a $9.2 \%$ lymphocytes (i.e., lymphocytopenia). Initially, the patient was receiving supportive treatment, but subsequently she developed respiratory failure warranting implementation of mechanical ventilation and admission to intensive care unit (ICU). Nineteen days after admission, she underwent pulmonary CT angiography due to high clinical suspicion of APE and elevation in D-dimer levels $(8,727 \mathrm{ng} / \mathrm{mL})$. CT angiogram confirmed bilateral filling defects in segmental and sub-segmental branches of pulmonary artery.

\section{Case 3}

Figure 3 belongs to a 38-year-old man hospitalized for 13 days. He presented with progressive dyspnea. On admission, he had WBC count of $4.9\left(10^{3} / \mu \mathrm{L}\right)$ with $67 \%$ neutrophils and $24.1 \%$ lymphocytes, $120,000$ platelets per micro liter, and elevated ESR ( $56 \mathrm{~mm} /$ hour $)$ and CRP (58 mg/L). On the ninth day of admission, the patient became a candidate for pulmonary CT angiography because of lack of response to therapies and rising $D$-dimer levels $(14,269 \mathrm{ng} / \mathrm{mL}$ on the sixth day vs $>15,000 \mathrm{ng} / \mathrm{mL}$ on the eighth day). CT angiogram confirmed APE. 

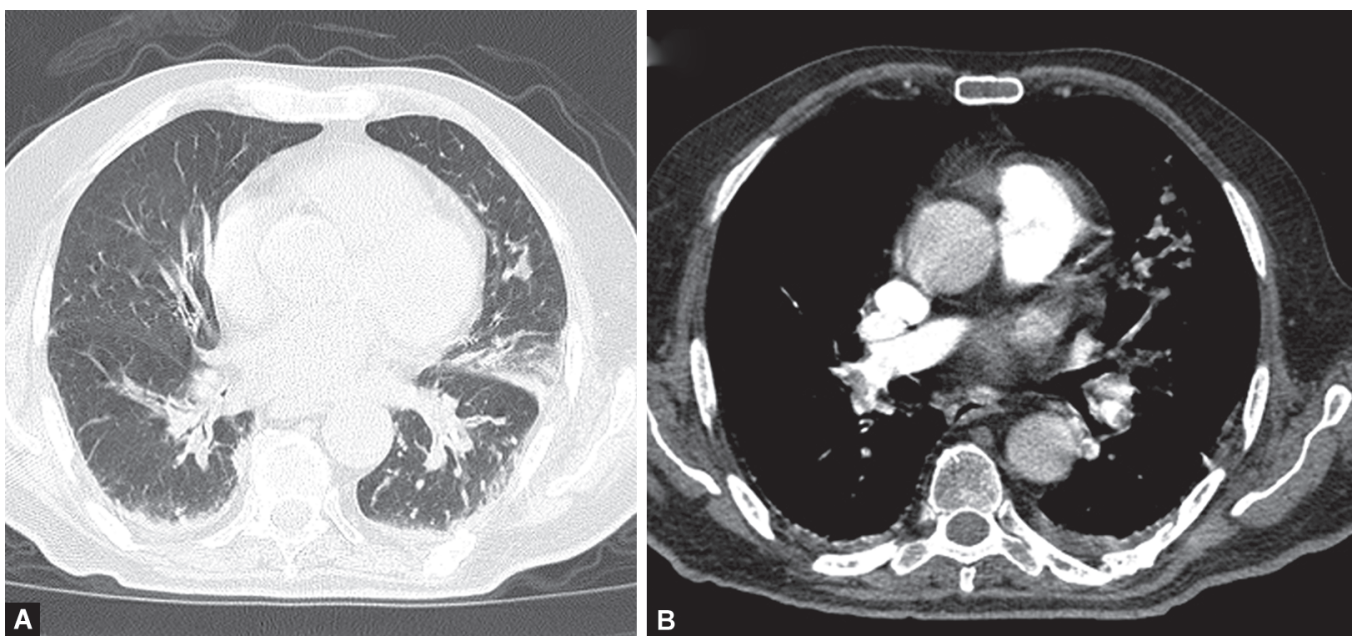

Figs $1 \mathrm{~A}$ and B: Images of an 86-year-old man with COVID-19 pneumonia: (A) Axial unenhanced chest CT obtained at the day of admission showing areas of ground glass and reticular opacity; (B) Axial pulmonary CT angiography demonstrating bilateral filling defects in lobar and segmental branches of the pulmonary artery
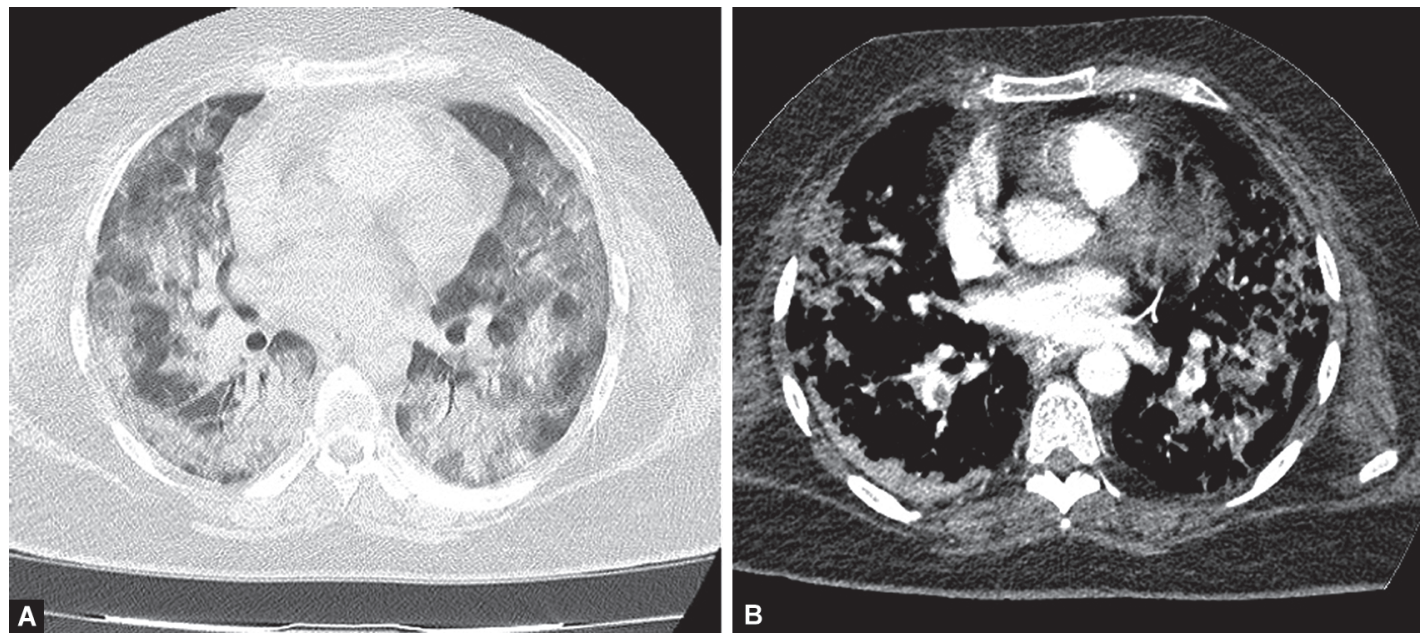

Figs $2 \mathrm{~A}$ and B: Images of a 42-year-old woman with COVID-19 pneumonia: (A) Axial unenhanced chest CT at the day of admission showing bilateral multilobar peripheral and peribronchovascular ground glass and consolidative opacities; (B) Axial pulmonary CT angiography confirming bilateral filling defects in segmental and subsegmental branches of the pulmonary artery
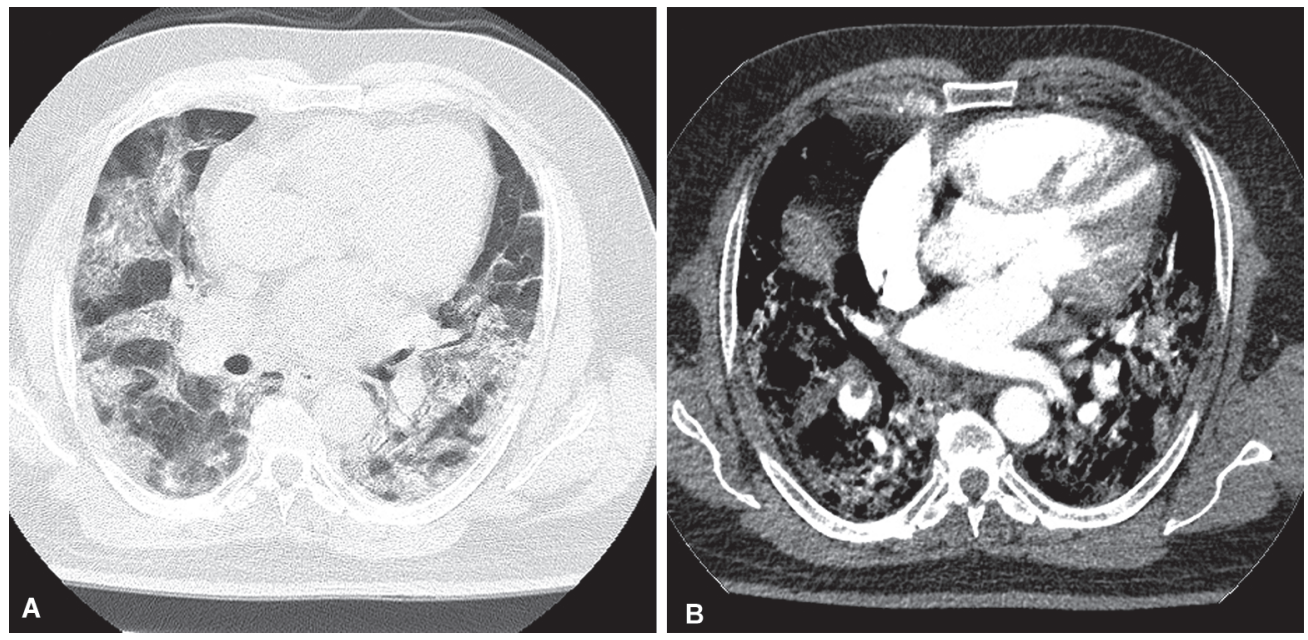

Figs 3A and B: Images of a 38-year-old man with COVID-19 pneumonia: (A) Axial unenhanced chest CT obtained at the first day of admission revealing bilateral ground glass opacities and areas of crazy paving; (B) Axial pulmonary CT angiogram showing filling defects in segmental branches of the pulmonary artery bilaterally 


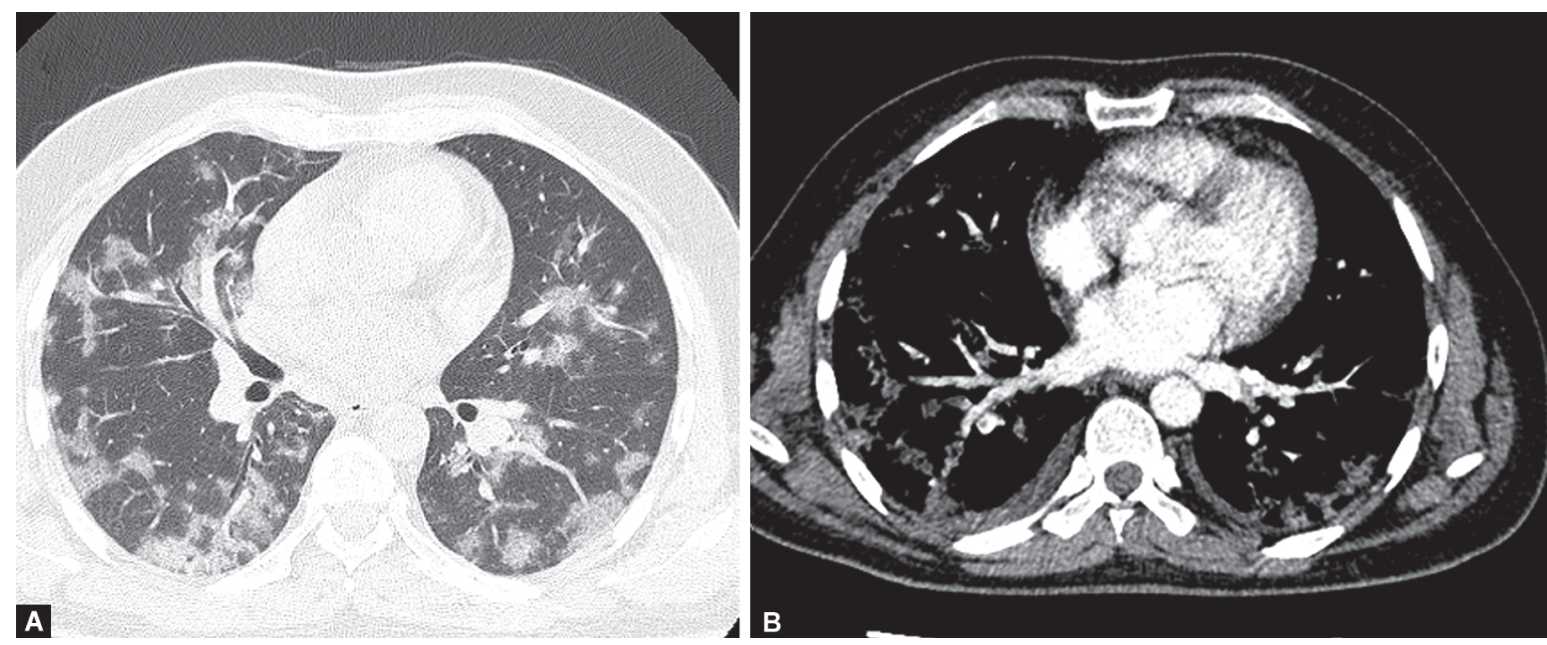

Figs 4A and B: Images of a 42-year-old man with COVID-19 pneumonia: (A) Axial unenhanced chest CT obtained at the first day of admission revealing bilateral ground glass opacities; (B) Axial pulmonary $\mathrm{CT}$ angiogram showing a filling defects in subsegmental branches of the pulmonary artery bilaterally

\section{Case 4}

Figure 4 shows the case of a 42 -year-old-man admitted to hospital because of fatigue, fever, dyspnea, and cough. On the fourth day, he experienced progressively worsening dyspnea and elevated D-dimer levels (>15,000 ng/mL); thus, a pulmonary CT angiography was performed. Filling defects were evident within the subsegmental branches of pulmonary artery on both sides.

After established diagnosis of APE, treatment with standard therapeutic doses of anticoagulants (low-molecular-weight Heparin $1 \mathrm{mg} / \mathrm{kg}$ every 12 hours) was initiated for all four patients. All the patients did well except the third case who died of acute respiratory distress syndrome.

\section{Discussion}

Critically ill patients are at increased risk of thromboembolic events mainly due to immobility; it is also known that acute severe infections can lead to increased risk of thromboembolic events per se. ${ }^{9}$ Previous studies have shown that patients with pneumonia are at two- to threefold increased risk of DVT. ${ }^{10}$ Undiagnosed or untreated APE can pose higher mortality risks in these patients. An association has been suggested between influenza-induced pneumonia and procoagulant states. ${ }^{11-13}$ APE has also been reported in one patient with severe acute respiratory syndrome (SARS). ${ }^{14}$ However, to the best of our knowledge, no cases of APE and Middle East Respiratory Syndrome (MERS), the other coronavirus reported previously, have been record. Since the beginning of the COVID-19 pandemic, three case reports have been published pointing out a possible association between the novel coronavirus pneumonia and APE with or without DVT. ${ }^{15-17}$ Evidences suggest that the coagulopathy associated with COVID-19 is a combination of low-grade DIC and localized microangiopathy. ${ }^{18}$ It has also been suggested that there is an association between the inflammatory cascade and the coagulation cascade. ${ }^{19}$ Taken together, it has been postulated that SARS-CoV2 can cause thrombosis formation.

Previous studies have reported elevated D-dimer levels in COVID-19 patients as a non-specific acute-phase reactant and baseline characteristic of critically ill patients. ${ }^{20-23}$ Although relying simply on D-dimer levels to diagnose APE and DVT in
COVID-19 patients may be misleading, elevated level of D-dimer has good negative-predictive value and can still be useful guide in management of critically ill patients with SARS-CoV2-induced pneumonia.

All our cases had higher-than-normal D-dimer levels, and none had recognized risk factors predisposing to thromboembolism except for decreased mobility and severe pneumonia. The present cases suggest that APE should be suspected in COVID-19 patients who follow a deteriorating course, and by clinical suspicion, pulmonary CT angiography should be conducted. In addition, the need is felt to find an optimal cutoff point value for D-dimer in SARS-CoV2-positive patients in order to diagnose DVT and APE with greater sensitivity and specificity. Consequently, the use of prophylactic doses of anticoagulants may be advocated.

\section{References}

1. Rothan HA, Byrareddy SN. The epidemiology and pathogenesis of coronavirus disease (COVID-19) outbreak. J Autoimmun 2020;109:102433. DOI: 10.1016/j.jaut.2020.102433.

2. Cascella M, Rajnik M, Cuomo A, Dulebohn SC, Di, Napoli R. Features, evaluation and treatment coronavirus (COVID-19). Treasure Island (FL): StatPearls; 2020.

3. Glober N, Tainter CR, Brennan J, Darocki M, Klingfus M, Choi M, et al. Use of the d-dimer for detecting pulmonary embolism in the emergency department. J Emerg Med 2018;54(5):585-592. DOI: 10.1016/j.jemermed.2018.01.032.

4. Han L, Dai L, Li HY, Lan F, Jiang WJ, Zhang HJ. Elevated D-dimer increases the risk of dialysis after surgery in patients with stanford a aortic dissection through the impact of the coagulation system. J Thorac Dis 2018;10(12):6783-6793. DOI: 10.21037/jtd.2018.11.138.

5. Douma RA, Le Gal G, Sohne M, Righini M, Kamphuisen PW, Perrier A, et al. Potential of an age adjusted D-dimer cut-off value to improve the exclusion of pulmonary embolism in older patients: a retrospective analysis of three large cohorts. BMJ 2010;340(3):c1475. DOI: 10.1136/ bmj.c1475.

6. Stals MA, Klok FA, Huisman MV. Diagnostic management of acute pulmonary embolism in special populations. Expert Rev Respir Med 2020;14(7):729-736. DOI: 10.1080/17476348.2020.1753505.

7. Li X, Wang L, Yan S, Yang F, Xiang L, Zhu J, et al. Clinical characteristics of 25 death cases with COVID-19: a retrospective review of medical records in a single medical center, Wuhan, China. Int J Infect 
Dis 2020;94:128-132. DOI: 10.1016/j.ijid.2020.03.053pii: S12019712(20)30186-7.

8. Wu C, Chen X, Cai Y, Xia J, Zhou X, Xu S, et al. Risk factors associated with acute respiratory distress syndrome and death in patients with coronavirus disease 2019 pneumonia in Wuhan, China. JAMA Intern Med 2020;180(7):934-943. DOI: 10.1001/jamainternmed.2020.0994.

9. Schmidt M, Horvath-Puho E, Thomsen RW, Smeeth L, Sorensen HT. Acute infections and venous thromboembolism. J Intern Med 2012;271(6):608-618. DOI: 10.1111/j.1365-2796.2011.02473.x.

10. Smeeth L, Cook C, Thomas S, Hall AJ, Hubbard R, Vallance P. Risk of deep vein thrombosis and pulmonary embolism after acute infection in a community setting. Lancet 2006;367(9516):1075-1079. DOI: 10.1016/S0140-6736(06)68474-2.

11. Van Wissen M, Keller TT, Ronkes B, Gerdes VE, Zaaijer HL, Van Gorp $E C$, et al. Influenza infection and risk of acute pulmonary embolism. Thromb J 2007;5(1):16. DOI: 10.1186/1477-9560-5-16.

12. Ohrui T, Takahashi H, Ebihara S, Matsui T, Nakayama K, Sasaki H. Influenza A virus infection and pulmonary microthromboembolism. Tohoku J Exp Med 2000;192(1):81-86. DOI: 10.1620/tjem.192.81.

13. Bunce PE, High SM, Nadjafi M, Stanley K, Liles WC, Christian MD. Pandemic H1N1 influenza infection and vascular thrombosis. Clin Infect Dis 2011;52(2):e14-e17. DOI: 10.1093/cid/ciq125.

14. Ng KH, Wu AK, Cheng VC, Tang BS, Chan CY, Yung CY, et al. Pulmonary artery thrombosis in a patient with severe acute respiratory syndrome. Postgrad Med J 2005;81(956):e3. DOI: 10.1136/pgmj.2004.030049.

15. Danzi GB, Loffi M, Galeazzi G, Gherbesi E. Acute pulmonary embolism and COVID-19 pneumonia: a random association? Eur Heart J 2020;41(19):1858. DOI: 10.1093/eurheartj/ehaa254pii: ehaa254.
16. Xie $Y$, Wang $X$, Yang P, Zhang S. COVID-19 complicated by acute pulmonary embolism. Radiology: Cardiothora Imag 2020;2(2):e200067.

17. Casey K, Iteen A, Nicolini R, Auten J. COVID-19 pneumonia with hemoptysis: acute segmental pulmonary emboli associated with novel coronavirus infection. Am J Emerg Med 2020;38(7):1544. e1-1544.e3. DOI: 10.1016/j.ajem.2020.04.011.

18. Levi M, Thachil J, Iba T, Levy JH. Coagulation abnormalities and thrombosis in patients with COVID-19. Lancet Haematol 2020;7(6):e438-e440. DOI: 10.1016/S2352-3026(20)30145-9.

19. Lupu F, Keshari RS, Lambris JD, Coggeshall KM. Crosstalk between the coagulation and complement systems in sepsis. Thromb Res 2014;133(Suppl 1):S28-S31. DOI: 10.1016/j.thromres.2014.03.014.

20. Huang C, Wang Y, Li X, Ren L, Zhao J, Hu Y, et al. Clinical features of patients infected with 2019 novel coronavirus in Wuhan, China. Lancet 2020;395(10223):497-506. DOI: 10.1016/S0140-6736(20) 30183-5.

21. Coronaviridae Study Group of the International Committee on Taxonomy Of $\mathrm{V}$. The species severe acute respiratory syndromerelated coronavirus: classifying 2019-nCoV and naming it SARS-CoV-2.NatMicrobiol2020;5(4):536-544.DOI:10.1038/s41564-0200695-z.

22. Chen N, Zhou M, Dong X, Qu J, Gong F, Han Y, et al. Epidemiological and clinical characteristics of 99 cases of 2019 novel coronavirus pneumonia in Wuhan, China: a descriptive study. Lancet 2020;395(10223):507-513. DOI: 10.1016/S0140-6736(20)30211-7.

23. The Lancet H. COVID-19 coagulopathy: an evolving story. Lancet Haematol 2020;7(6):e425. DOI: 10.1016/S2352-3026(20)30151-4. 